\title{
Surgical removal of a telemetry system in a cynomolgus monkey (Macaca fascicularis): a 12-month observation study
}

\author{
Doo-Wan Cho ${ }^{1+}$, Hyoung-Yun Han ${ }^{2+}$, Mi-Jin Yang ${ }^{1}$, Dong Ho Woo ${ }^{3}$, Su-Cheol Han ${ }^{1}$ and Young-Su Yang ${ }^{1 *}$ (D)
}

\begin{abstract}
Background: Telemetry is a wireless implanted device that measures biological signals in conscious animals and usually requires surgery for its removal when the study is finished. After removing the device, the animals are either used for other studies or euthanatized.

Case presentation: Herein, we report the case of a living cynomolgus monkey (Macaca fascicularis) that was used for the entire experimental period, instead of euthanasia, after surgical removal of an implanted telemetry system. Radiography was used to determine the status of the implanted telemetry, following which, a repair surgery was performed for removing the system; clinical signs were used to preserve the life of the cynomolgus monkey. Postoperative clinical signs, food consumption, hematology, and serum biochemistry were examined during the 12-month observational period. No abnormal readings or conditions were observed in the subject after implant removal.
\end{abstract}

Conclusions: This study may be a useful case report for living cynomolgus monkeys in telemetry implantations used throughout the study period. We suggest minimizing the suffering and improving the welfare of these animals.

Keywords: Cynomolgus monkey, Surgery, Telemetry, Implantation, Welfare

\section{Background}

When evaluating a new pharmaceutical product, the essential requisite is the drug's safety, particularly, the potential cardiovascular effects in humans. As a result, safety assessments are performed following the International Council on Harmonization guidelines. Precise and detailed measurements are required, especially, of arterial pressure because of its narrow physiological safety range. The cardiovascular system is particularly vulnerable to changes depending on the animal's environmental comfort. For this reason, implanted telemetric systems

\footnotetext{
*Correspondence: ysyang@kitox.re.kr

${ }^{\dagger}$ Doo-Wan Cho and Hyoung-Yun Han have contributed equally to this manuscript

' Jeonbuk Branch Institute, Korea Institute of Toxicology, Jeongeup, Republic of Korea

Full list of author information is available at the end of the article
}

have been developed and widely used [1-3]. The telemetry systems installed have been specifically designed to allow data collection without human contact interference to ensure accurate blood pressure readings and electrocardiogram waveforms during the entire study period.

The primary types of animals used for testing with such telemetry systems are rodents, dogs and primates. Regarding the insertion and management of telemetric sensors, more attention is needed in primate species because of their smaller abdominal cavities and picking at sutured skin margins around an implant, complicating healing. The animals receiving telemetric implants recover after approximately 2-3 weeks and eventually undergo pharmacological safety tests for about two and a half years. At this point, the sensor battery is no longer effective, and the sensor is removed. Most animals are killed at the end of studies for scientific or humane reasons [4]. In addition, some countries have 
legal constraints that apply to their reuse. Some animals are reused or rehomed. However, there are no reports on reused animals after telemetry implant removal surgery.

In this study, we report the case of a reused animal and described its health data during a postoperative 12-month observational period.

\section{Case presentation}

Animals were housed and maintained in the specific pathogen-free (SPF) facility at the Korea Institute of Toxicology (KIT), according to KIT Animal Care and Use Committee Guidelines. All monkeys were kept in an indoor individual cage and was fed commercial monkey chow (Certified Primate Diet \#5048, PMI Nutrition International, Inc., USA) supplemented daily with various fruits, and supplied water ad libitum. The temperature, humidity, and light cycle were automatically controlled $\left(20-29{ }^{\circ} \mathrm{C}\right.$, relative humidity $40-70 \%, 12 \mathrm{~h}$ light/dark cycle with 300-700 lx). This study was conducted with the approval of the Animal Experiment Ethics Committee (KIT IACUC number: 1609-0325).

Six male cynomolgus monkeys (Macaca fascicularis), also known as the long-tailed macaque, were used in the tests and the telemetry system that had been installed for 28 months was removed in one monkey. This was because this animal was rarely used in toxicological studies than the others. On the day preceding the implant removal surgery, the subject was fasted and general anesthesia was induced via intramuscular ketamine injection. A radiography (Fig. 1A) was performed after anesthesia induction and the intricacies of the sensor location and installation were verified, and the removal procedure was initiated. The animal was intubated and artificially ventilated using a mixture of oxygen and volatile anesthetic (isoflurane 1-2\%), throughout the operation. The animal's mid-abdominal region was shaved, depilated, disinfected by using a 2 -stage surgical scrub with $70 \%$ ethanol and povidoneiodine, and covered with a sterile surgical drape. An incision was made along the linea alba using an electrosurgical scalpel, which minimized bleeding. Upon opening the abdominal cavity, the transmitter was encapsulated by tissue, surrounded by attached connective, omentum, and fatty tissues (Fig. 1B). The transmitter was extracted by carefully removing the sensor anchor as well as the surrounding soft tissue and sensor lines fixed to the peritoneum. The abdominal cavity was cleaned twice with sterile physiological saline. Once the rinsing was complete, the abdominal wall was closed in layers using the simple interrupted suture pattern and 4-0 absorbable suture material, and the subcutaneous tissue closed using a continuous suture pattern and 4-0 Vicry ${ }^{\circledR}$ Ethicon absorbable suture material. The skin margin was closed using simple interrupted suture pattern and 4-0 non-absorbent suture material. Antibiotics (cefazolin sodium $20 \mathrm{mg} / \mathrm{kg}$, b.i.d., five days; Chong Kun Dang Pharm) and analgesics (ketoprofen; $2 \mathrm{mg} / \mathrm{kg}$, s.i.d., five days; UNIBIOTECH) were administered after the surgery, and no particular abnormalities were observed, based on the results of the clinical
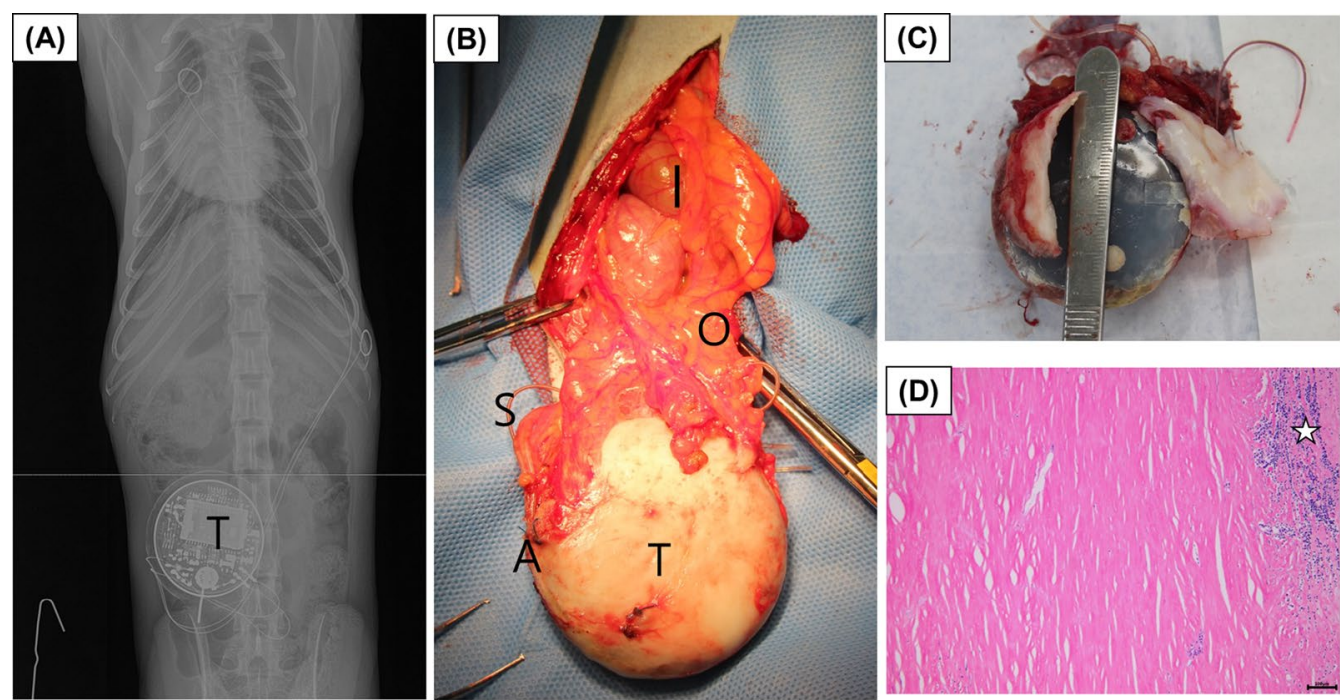

Fig. 1 Images for experimental procedures. X-ray image was before the removal surgery (A). A transmitter was removed by surgical method (B) and it was capsuled by fibrous substance (C) that was composed with collagen fiber and slight lymphocyte infiltrated (white star) in microscopic examination (D) (Scale bar $=100 \mu \mathrm{m})$. Alphabets in image were Intestine (I), Omentum (O), Sensor (S), Transmitter (T) and Attachment site in abdominal wall (A) 
observation, hematological and biochemical tests conducted postoperatively (Additional file 1: Table S1).

Postoperative radiography was performed, and microscopic examination of the tissue wrapping the transmitter showed that some lymphocytes were present in the excised fibrous tissue (Fig. 1D). Twelve months after the removal, the animal showed no unusual findings in clinical signs, food consumption, and clinical chemistry examination results (Table 1).

\section{Discussion and conclusions}

The animal that had removal surgery was exposed to new materials in a single low volume, and no particular unusual findings were observed in the general symptoms and feed collection observations prior to the sensor removal operation. The fibrous substance observed in the animal may be a protective mechanism elicited by the body against external materials [5]. This was considered as a complex wound healing response to the presence of biomedical device with diverse cell signaling, followed by migration of fibroblasts to the implant surface. Eventually, it is walling off of the implant in a collagen capsule. Similar results has been reported in experiment with implanting other biomedical devices into the experimental animals [6].

After removing the transmitter, we regularly examined clinical signs, food consumption, body weight, and clinical pathology, and no uneventful findings were

Table 1 Clinical chemistry results were for implant surgery (pre and post data) and removal surgery (pre and post data)

\begin{tabular}{|c|c|c|c|c|}
\hline \multirow[t]{2}{*}{ Parameters } & \multicolumn{2}{|c|}{ Implant surgery } & \multicolumn{2}{|c|}{ Removal surgery } \\
\hline & Pre (Day -7) & $\begin{array}{l}\text { Post (Day } \\
\text { 14) }\end{array}$ & $\begin{array}{l}\text { Pre (Day } \\
-30)\end{array}$ & $\begin{array}{l}\text { Post } \\
\text { (12 months } \\
\text { later) }\end{array}$ \\
\hline GLU (mg/dL) & 96.7 & 69.4 & 62.8 & 75.8 \\
\hline BUN (mg/dL) & 19.3 & 18.9 & 19.9 & 16.2 \\
\hline $\begin{array}{l}\text { CREA (mg/ } \\
\mathrm{dL} \text { ) }\end{array}$ & 0.83 & 0.86 & 0.74 & 0.75 \\
\hline TP (g/dL) & 7.27 & 8.31 & 7.17 & 7.68 \\
\hline ALB (g/dL) & 4.38 & 4.69 & 4.14 & 4.54 \\
\hline A/G (ratio) & 1.52 & 1.3 & 1.37 & 1.45 \\
\hline AST (IU/L) & 36.9 & 47.8 & 25.9 & 36.5 \\
\hline ALT (IU/L) & 31.8 & 37.6 & 24.5 & 24.2 \\
\hline TBIL (mg/dL) & 0.303 & 0.363 & 0.238 & 0.268 \\
\hline GGT (IU/L) & 87.72 & 80.04 & 66.1 & 56.89 \\
\hline $\begin{array}{l}\mathrm{RBC}(\times 10 \wedge 6 / \\
\mu \mathrm{L})\end{array}$ & 6.33 & 6.41 & 6.25 & 6.3 \\
\hline $\begin{array}{l}\text { WBC }\left(\times 10^{3} /\right. \\
\mu \mathrm{L})\end{array}$ & 12.03 & 18.06 & 11.55 & 8.66 \\
\hline $\begin{array}{l}\mathrm{NEU}\left(\times 10^{3} /\right. \\
\mu \mathrm{L})\end{array}$ & 5.65 & 12.85 & 6.31 & 3.17 \\
\hline
\end{tabular}

noted. Microbiological tests were periodically conducted on the monkey, such as for Salmonella, Shigella, and Yersinia, and no parasites were isolated from fecal samples. During social housing with other animals, the animal played well and groomed each other. One year later, the animal remained healthy without any abnormal health conditions when compared with agedmatched surgery-naïve animals. The animal is currently being used for non-invasive laboratory procedures (mating and semen extraction).

Recently, various sensors or devices used to obtain physical data, cardiovascular effects, and blood glucose measurements have been developed and inserted into animal bodies for accurate and continuous testing results from a conscious, movement-free situation [2, $7,8]$. Most animals used in such studies are euthanized at the end of the study. However, we need to consider whether euthanasia is the only effective and convenient method for the experimenter. When making the final judgment, we should take into account the scientific and ethical problems of reusing animals and obtain the opinions of the Institutional Animal Care and Use Committees (IACUC) committee members and make a final decision $[7,8]$.

In this study, we present the long-term animal health data after surgical removal of a telemetry implant. However, this is a single case report with a monkey, more reports or clinical trials with other animals study are needed. We hope that this study may help to determine the fate of animals used in telemetry studies.

\section{Abbreviations}

ALB: Albumin; ALT: Alanine aminotransferase; AST: Aspartate aminotransferase; A/G: Albumin/globulin ratio; BUN: Blood urea nitrogen; CREA: Creatinine; GGT : Gamma glutamyl transpeptidase; GLU: Glucose; NEU: Neutrophil; RBC: Red blood cell; TBIL: Total bilirubin; TP: Total protein; WBC: White blood cell.

\section{Supplementary Information}

The online version contains supplementary material available at https://doi. org/10.1186/s42826-021-00106-z.

Additional file 1: Table S1. Clinical chemistry results for implant surgery (pre and post data) in five animals. Telemetry device was implanted in six animals and removal surgery was conducted in only one animal. Other five animals were euthanized in accordance with the study design.

\section{Acknowledgements}

The author would like to thank P.S. Lee, D.H. Jung, J.W. Lee, J.W. Jang and J.M. Jang for caring for all NHPs.

\section{Authors' contributions}

Conceptualization: Han HY, Yang YS; Data curation: Cho DW; Investigation: Cho DW; Methodology: Yang MJ, Yang YS; Project administration: Yang YS; Supervision: Han SC, Woo DH; Visualization: Yang MJ; Writing - original draft: Cho DW, Han HY; Writing - review \& editing: Han SC, Woo DH, Yang YS. All authors read and approved the final manuscript. 


\section{Funding}

This work was supported by a grant (KK-2107 and KK-2101) from the Korea Institute of Toxicology, Korea.

\section{Availability of data and materials}

The authors confirm that the data supporting the findings of this study are available within the article [and/or] its supplementary materials.

\section{Declarations}

\section{Competing interests}

The author(s) declared no potential conflicts of interest with respect to the research, authorship, and/or publication of this article.

\section{Author details}

'Jeonbuk Branch Institute, Korea Institute of Toxicology, Jeongeup, Republic of Korea. ${ }^{2}$ Molecular Toxicology Research Group, Korea Institute of Toxicology, Daejeon, Republic of Korea. ${ }^{3}$ Pharmacology \& Drug Abuse Research Group Korea Institute of Toxicology, Daejeon, Republic of Korea.

Received: 17 August 2021 Accepted: 6 October 2021

Published online: 16 October 2021

\section{References}

1. Baird TJ, Bailie M, Patrick DJ, Moddrelle D, Yoder J, Gauvin DV, et al. Influence of surgically implantable telemetry solutions on in-life and post-mortem toxicology endpoints. J Pharmacol Toxicol Methods. 2013;67(3):148-61.
2. Chaves AA, Keller WJ, O'sullivan S, Williams MA, Fitzgerald LE, McPherson $\mathrm{HE}$, et al. Cardiovascular monkey telemetry: sensitivity to detect QT interval prolongation. J Pharmacol Toxicol Methods. 2006;54(2):150-8.

3. Hassimoto M, Harada T. Use of a telemetry system to examine recovery of the cardiovascular system after excitement induced by handling stress in a conscious cynomolgus monkey (Macaca fascicularis). J Med Primatol. 2003;32(6):346-52.

4. Morton DB, Hawkins P, Bevan R, Heath K, Kirkwood J, Pearce P, et al. Refinements in telemetry procedures: seventh report of BVAAWF/FRAME/ RSPCA/UFAW Joint Working Group on Refinement. Part A Lab Anim. 2003;37(4):261-99.

5. Niehoff MO, Niggemann B, Sternberg J, Jenkins A, Holbrook M. Measurement of hyper-and hypotension during repeated dose toxicity studies in either freely moving or physically restrained cynomolgus monkeys. J Pharmacol Toxicol Methods. 2014;70(3):268-75.

6. DiEgidio P, Friedman HI, Gourdie RG, Riley AE, Yost MJ, Goodwin RL. Biomedical implant capsule formation: lessons learned and the road ahead. Ann Plast Surg. 2014;73(4):451-60

7. Veiseh O, Doloff JC, Ma M, Vegas AJ, Tam HH, Bader AR, et al. Size-and shape-dependent foreign body immune response to materials implanted in rodents and non-human primates. Nat Mater. 2015;14(6):643-51.

8. Wang B, Sun G, Qiao W, Liu Y, Qiao J, Ye W, et al. Long-term blood glucose monitoring with implanted telemetry device in conscious and stress-free cynomolgus monkeys. J Endocrinol Invest. 2017;40(9):967-77.

\section{Publisher's Note}

Springer Nature remains neutral with regard to jurisdictional claims in published maps and institutional affiliations.
Ready to submit your research? Choose BMC and benefit from:

- fast, convenient online submission

- thorough peer review by experienced researchers in your field

- rapid publication on acceptance

- support for research data, including large and complex data types

- gold Open Access which fosters wider collaboration and increased citations

- maximum visibility for your research: over $100 \mathrm{M}$ website views per year

At BMC, research is always in progress.

Learn more biomedcentral.com/submissions 